\title{
Familial Mediterranean Fever: A Retrospective Clinical and Molecular Study in the East of Anatolia Region of Turkey
}

\author{
Ebru Onalan Etem*, Sukriye Derya Deveci, Deniz Erol, Huseyin Yuce and Halit Elyas
}

Firat University, Firat University Hospital, Medical Biology and Genetic Department, 23119, Elazig, Turkey

\begin{abstract}
Familial Mediterranean Fever (FMF) is an autoinflammatory periodic disorder. We aim to identify the distribution and the frequency of the Mediterranean Fever (MEFV) gene mutations in the east of Anatolia in Turkey and perform a genotype/phenotype correlation in the patients' cohort. The study was carried out on 415 clinically diagnosed Turkish FMF patients and 103 healthy controls. The tested individuals were screened for the most common twelve MEFV mutations. The most important features were the predominance of the M694V and E148Q mutations in patient group and the earlier of onset of the disease in M694V mutation carriers compared with the carriers of other mutations $(\mathrm{P}=0.00)$. We discuss the high frequency of E148Q mutations in patient group compared with controls, genetic counseling in intermarriage families and the variations in mutation frequency according to regions of Turkey.
\end{abstract}

Keywords: Familial mediterranean fever, mutation screening, genetic counseling, M694V mutation.

\section{INTRODUCTION}

Despite its striking symptom pattern, Familial Mediterranean Fever (FMF; MIM\# 249100), was first described as a distinct entity in 1945 [1]. FMF, the most frequent hereditary recurrent fever, is an autosomal recessive disease that affects commonly populations of Armenian, Arab, Sephardic Jewish or Turkish origin and it is not uncommon in other Mediterranean populations, such as Italians, Spanish, Portuguese, French, and Greeks [2, 3]. The historic trace-back of the shared haplotype and common mutations suggests a common ancestor at least 2000 years ago, when most of these populations were living together in the eastern Mediterranean basin, around Mesopotamia [3-6]. The carrier frequency of MEFV mutations is quite high in the 4 classically affected populations, ranging from $37-39 \%$ in Armenians and Iraqi Jews to $20 \%$ in Turks, North African and Ashkenazi Jews, and Arabs [1].

Although an unexplained clinical heterogeneity is not uncommon, the diagnosis of the disease, which is based on various sets of clinical criteria $[2,7]$, can be confirmed by molecular means that provides the only objective diagnostic criterion in the absence of functional test. In 1997 the gene linked to FMF, called MEFV, was cloned from to chromosome 16p using positional cloning and some of the mutations associated with the disease were identified $[1,6]$. The gene comprises 10 exons, spanning approximately $15 \mathrm{~kb}$ of genomic DNA and encodes a 781 amino acid-long protein. All four of the initial FMF-associated mutations in MEFV were in exon 10 , and even now, with over 55 mutations having been identified (see the Infevers database of FMF and hereditary autoinflammatory disorders mutations online at http://fmf.igh.cnrs.fr/infevers), exon 10

*Address correspondence to this author at the Firat University, Firat University Hospital, Medical Biology and Genetic Department, 23119, Elazig, Turkey; Tel; +9004242370000/4656;

E-mail: ebruetem@gmail.com remains the major site of mutations, with a smaller cluster in exon $2[2,5,6]$. Nearly all of the known FMF-associated mutations encode conservative missense changes [8-10]. The most frequent mutations (M 680 I, M 694 V, V726 A, M 694 I and $\mathrm{E} 148 \mathrm{Q}$ ) are found in more than two thirds of cases $[10,11]$.

The protein encoded by the MEFV gene, termed pyrin or marenostrin, includes a PYRIN domain (PYD), which has been already analyzed crystallographically [12]. Pyrin presumably participates in a complex interplay with the PYD protein superfamily, lipopolysaccharide (LPS) via Toll-like receptor family and procaspase-1 activation, and is implicated in the homeostatic control of inflammation through leukocyte apoptosis, IL-1 $\beta$, and NF- $\mathrm{BB}$ pathway activation [13-15]. However, the precise function of the entire pyrin protein is still unknown $[1,5,6]$.

Molecular analysis of MEFV is a useful tool in clinical practice, mainly in the atypical forms of the disease [16]. However, many clinically typical FMF patients are heterozygous or no disease-associated mutations are found [16-18]. The incomplete penetrance and the varying expression of FMF suggest the presence of other, possibly genetic, factors that could influence the expression of illness $[4,19]$. Colchicine is the preferred drug for FMF [17]. Genotype-phenotype correlation, thoroughly studied over the past few years, suggested that mutations located within the mutational hotspots in codons 680 and 694 are associated with severe disease, early onset, high frequency of attacks, the necessity of a high dose of colchicine to control attacks, and frequent occurrence of amyloidosis in untreated patients [20].

The present study aim to investigate the twelve most common MEFV mutations frequency in the east of Anatolia in Turkey and to compared these results with the studies performed in other regions of Turkey, in order to provide a link which will facilitate the clinical interpretation of individualized genetic data and to evaluate the phenotypic 
features of Turkish FMF patients with the E148Q mutation in homozygous, heterozygous, and complex states in order to shed light on the clinical presentation of this mutation compared with healthy subjects.

\section{MATERIALS AND METHODOLOGY}

\section{Study Design and Patients}

The study was approved by the Human Studies Ethics Committee of Firat University Hospital in the east of Anatolia region of Turkey. Clinical data on these patients were obtained from the records of Firat University Hospital. All patients were obtained at the Pediatric Clinic and Rheumatology Clinic of Firat University Hospital and a number of medical centers in the east of Anatolia region on Turkey. Diagnosis of FMF patients was established according to previously described criteria [11]. All of them were interviewed directly by one of clinicians with identical clinical forms. These included patients meeting clinical criteria for FMF who desired genetic confirmation of the diagnosis; individuals with unexplained fever, abdominal pain, or arthritis atypical of FMF who were seeking a diagnosis; and several asymptomatic relatives of patients. The diagnosis of FMF was based on a typical clinical picture of recurrent attacks of fever and pain affecting patients, and involving one or two of the following sites at a time: abdomen, chest, joints, muscles, scrotum, and skin. In addition, an increase in acute phase reactants during the attacks, a positive history among siblings or in the extended family, and a good response to colchicine helped to establish the diagnosis. We viewed the records of all patients and looked at the following details: family origin; age of onset; clinical features (fever, abdominal, thoracic, articular, skin, muscular, testicular, and miscellaneous manifestations); severity of the disease by number of attacks per month and duration of attack. The study group included 1100 patients, who were clinically suspected as FMF and 103 healthy controls.

\section{Genetic Testing}

$2 \mathrm{ml}$ blood samples were collected from all subjects. Genomic DNA was extracted from whole blood by means of the Promega Wizard ${ }^{\circledR}$ Genomic DNA Purification Kit (Promega, USA). Twelve common MEFV gene mutations located in exon 2 (E148Q), exon 3 (P369S), exon 5 (F479L), and exon 10 [M680I (G/C), M680I (G/A), I692del, M694V, M694I, K695R, V726A, A744S, and R761H] were studied with a reverse hybridization assay as described by the manufacturer (FMF Strip Assay; Vienna Lab Labordiagnostika GmbH, Vienna, Austria) [21].

103 unrelated population-matched healthy controls were enrolled in the study for detection M694V, V726A, M680I, E148Q, M694I, P369S, A744S and R761H mutation rate. Mutation identification in healtly controls was performed according to previously described techniques. The mutations were assessed by amplifying the genomic DNA template with amplification refractory mutation system (ARMS) or restriction fragment length polymorphism (RFLP) $[1,22]$.

\section{Genetic Counseling}

Genetic counseling was given by counselors who have, besides their training in genetics, substantial experience in an
FMF clinic. We aim to identify couples who are at risk of giving birth to children affected with FMF disease.

\section{Statistical Analysis}

Data were analyzed using the SPSS program (SPSS Inc, Chicago, IL, USA). Comparisons among groups of patients with different combination of mutations in diagnosed FMF patients clinically and mutation anlysis were done by analysis of variance. Categorical variables were compared by using the $\mathrm{x}^{2}$ test. Differences between the proportion of patients with diagnosed FMF and the proportion with ethnicaly mathod healthy control populations were compared statisticaly by the two tailed Fisher's exact test.

\section{RESULTS}

The analysis of clinical features showed classical patterns. The majority of the patients had fever and abdominal pain during attacks, less frequently thoracic pain and arthritis and rarely amyloidosis. Table 1 summarizes clinical symptoms of 415 patients. The majority of patients experienced an increase of the frequency and intensity of attacks following a stressing event (324/430, 75.3\%).

Table 1. Phenotypic Features of 415 FMF Patients

\begin{tabular}{|l|c|}
\hline \multicolumn{1}{|c|}{$\mathbf{N}=\mathbf{4 1 5}$} & Frequency (\%) \\
\hline \hline Male/Female & $251 / 179$ \\
\hline Age at onset (yr \pm SD) & $13.9 \pm 9.8$ \\
\hline Abdominal pain & $386(93.0 \%)$ \\
\hline Fever & $379(91.3 \%)$ \\
\hline Arthritis & $242(58.3 \%)$ \\
\hline Chest pain & $17(4.0 \%)$ \\
\hline Erysipelas-like erythema & $9(2.1 \%)$ \\
\hline Family history of FMF & $238(57.3 \%)$ \\
\hline Family history of amyloidosis & $3(0.7 \%)$ \\
\hline
\end{tabular}

415 of 1100 patients suspected as FMF were diagnosed as having FMF according to Yalcinkaya et al. [11]. Of these 415 patients, 251 were males and 179 were females; 268 were adult patients and 162 were children. 64 (23.8\%) adults patients were married to their relatives and the parents of 21(12.9\%) children patients were relative.

Among the 586 of 1100 patients, 10.2\% (60/586) were homozygotes, $30.8 \%(181 / 586)$ compound heterozygotes and $58.8 \%(345 / 586)$ heterozygotes. No mutation was found in the remaining 514 of FMF patients. It was not found the clinical findings in $51.5 \%(178 / 345)$ of heterozygotes mutation carrier patients. Seven of 415 clinically FMF patients did not found any mutation. But, we detected clinical features in addition to high fibrinogen and CRP levels in patients serum during attacks in seven patients with negative mutation analysis result. These patients were only the carrier for MEFV gene mutation without clinical symptoms. The detected mutations were mainly M694V, V726A, M680I and E148Q. The only rare ones were K695R, M694I and F479L. The distribution of FMF mutations in the study groups is given in Table $\mathbf{2}$. Table $\mathbf{3}$ showed the 
Table 2. Distributions of Alleles in Studies of Different Groups from Turkey

\begin{tabular}{|c|c|c|c|c|c|c|c|c|}
\hline Author & $\mathbf{n}$ & $\begin{array}{l}\text { No FMF } \\
\text { Patients }\end{array}$ & $\begin{array}{c}\text { Allele } \\
\text { Number }\end{array}$ & M694V & V726A & M680I & E148Q & $\begin{array}{l}\text { Other/Undefinied } \\
\text { Mutation }\end{array}$ \\
\hline Akin et al. [23] & 1,201 & $654(54.5 \%)$ & 2,402 & $375(15.6 \%)$ & $102(4.2 \%)$ & $94(3.9 \%)$ & $132(5.5 \%)$ & $391(16.3 \%)$ \\
\hline Ozturk et al. [24] & 201 & $83(41.3 \%)$ & 402 & $210(52.2 \%)$ & $6(1.5 \%)$ & $6(1.5 \%)$ & $14(3.5 \%)$ & $0(0 \%)$ \\
\hline Solak et al. [25] & 202 & $0(0 \%)$ & 404 & $146(36.1 \%)$ & $37(9.2 \%)$ & $48(11.9 \%)$ & $56(13.9 \%)$ & $117(29.0 \%)$ \\
\hline Yigit et al. [28] & 625 & $151(24.2 \%)$ & 1,250 & $421(33.7 \%)$ & $62(5.0 \%)$ & $194(15.5 \%)$ & $42(3.4 \%)$ & $229(18.3 \%)$ \\
\hline Yilmaz et al. [10] & 450 & $104(23.1 \%)$ & 900 & $464(51.6 \%)$ & $28(3.1 \%)$ & $84(9.3 \%)$ & $29(3.2 \%)$ & $87(9.7 \%)$ \\
\hline Yalcinkaya et al. [11] & 167 & - & 334 & $137(41 \%)$ & $48(14 \%)$ & $53(16 \%)$ & - & $41(\% 12)$ \\
\hline Tastan et al. [29] & 58 & - & 116 & $78(67.2 \%)$ & $18(15.5 \%)$ & $14(12.0 \%)$ & - & - \\
\hline Our studies & 1.100 & 685 & 830 & $180(21.6 \%)$ & $81(9.7 \%)$ & 79 (9.5\%) & $159(19.1 \%)$ & $331(39.8 \%)$ \\
\hline
\end{tabular}

mutation results of 415 patients with one and more mutations for determine the general mutation profile in the east of Anatolia. The most common mutation in patients group was M694V, followed by E148Q, V726A and M680I. We did not detect a I692del mutation in patient group. A familial history of the disease was noticed in $56.3 \%$ of the patients and the females/males ratio was estimated to $1.4(251 / 179)$.

Table 3. Mutation Profiles of 415 Patients with FMF

\begin{tabular}{|c|c|}
\hline Alleles (830) & Number/Frequencies \\
\hline \hline M694V & $180(21.6 \%)$ \\
\hline E148Q & $159(19.1 \%)$ \\
\hline V726A & $81(9.7 \%)$ \\
\hline M680I & $79(9.5 \%)$ \\
\hline P369S & $31(3,7 \%)$ \\
\hline R761H & $17(2.0 \%)$ \\
\hline A744S & $11(1.3 \%)$ \\
\hline K695R & $8(0,9 \%)$ \\
\hline M694I & $8(0,9 \%)$ \\
\hline F479L & $1(0,1 \%)$ \\
\hline Other/undefined mutation & $255(30.7 \%)$ \\
\hline
\end{tabular}

We assessed the relations between all mutations and clinical characteristic in 415 FMF patients. The mean age of onset of the disease was the lower in M694V mutation carrier (9.3 years) compared with other mutations carriers (13.2 years) $(\mathrm{P}=0.00)$ by Mann-Whitney $\mathrm{U}$ test. However, It was not detected any association between other clinical characteristics and the specific mutations.

In the healthy controls group, mutation analysis showed that $24(23.3 \%)$ of the subjects were carrying at least one mutated MEFV allele. The frequencies of E148Q, M694V, M694I, V726A and P369S mutation carriage were $12.6 \%$ (with 13/206 allele frequency), 5.8\% (6/206), 1.9\% (2/206), $1.9 \% \quad(2 / 206)$ and $0.9 \% \quad(1 / 206)$, respectively. The distribution of the eight most common mutations among healthy individulas was significantly different from that found in patients. The overall allele frequency calculated from the mutation frequencies in the healthy controls was $12 \%$ for E148Q. Compared with healthy controls (12\%), FMF patients (19.1\%) showed high E148Q allele frequencies by fisher's exact test $(\mathrm{p}=0.001)$.

E148Q mutation was detected in 159 patients, 37 patients were compound heterozygous and 123 patients were heterozygous. It was clinically diagnosed FMF in 25 of 37 compound heterozygous for E148Q mutation, eighteen were carrying E148Q/M694V, three were carrying E148Q/P369S, one was carrying E148Q/V726A, one was carrying E148Q/M680I, E148Q/K695R, and one was carrying E148Q/M680I. One was carrying E148Q/P369S/A744S of 123 heterozygotes patients for E148Q carrier.

Genetic counseling was given all patients with homozygous, heterozygous, complex states or negative result. We advice to get genetic test done the siblings of patients with homozygous, compound homozygous, heterozygous mutation carrier and clinically diagnosed FMF and thirty two patients with second and third degree or more distant relatives to make marriage.

\section{DISCUSSION}

In the present study, we report the frequencies of the twelve most common MEFV mutations among Turkish FMF patients in the east of Anatolia region and the phenotype/ genotype correlations in those FMF patients. This is the first study reporting MEFV gene mutation profile in the east of Anatolia and significant evidence for the undefined mutations in patients with E148Q mutation carrier. Our results are in agreement with the most frequent four mutations from the other study groups from Turkey [10, 11, 21-30].

In the studies by Touitou et al. [4], and by the Turkish FMF study group [31], the most common MEFV mutation in 
Turkey is M694V (57.0 and 51.4\%, respectively), followed by M680I (16.5 and 14.4\%, respectively), and V726A (13.9 and $8.6 \%$, respectively). Evaluating other studies in Turkish population, carrier rates for four common MEFV gene mutations may appear to vary regionally (Table 2). Range of the frequencies of four common mutations in FMF patients were $15.6-67.2 \%$ for M694V, $1.5-14 \%$ for V726A, 1.5$19.8 \%$ for M680I, for 3.2-30.8\% for E148Q. Frequencies in our study were within the previously reported range. Possible explanations for the divergent frequencies of mutation rates in FMF patients may be population, geographical, environmental or genetic heterogeneities, patients' inclusion criteria, methodological detection problems. In 12 population studies in Turkey, the mutations were genetically analyzed with many different techniques: sequencing, PCR-FLP, multiplex PCR, PCR-ELISA, reverse hybridization, ARMS, DGGE etc. [10, 11, 21-30].

The M694V mutation was the most common one (21.8\%) of the tested alleles in this cohort study (Table 3 ), as it was already reported in Turkish population and other populations $[4,9,32-35]$. The Turkish FMF study group demonstrated the close relationship between the M694V mutation and the severity of disease [31]. Some studies reported that the highest severity scores were observed in patients carrying the M694V mutation [11, 36]. Tunca et al. reported that patients with the M694V/M694V genotype were found to have an earlier age of onset and higher frequencies of arthritis and arthralgia compared with the other genotypes [37]. This study reveals an association between the earlier of the onset of the disease and the presence of mutation in codon 694 of exon 10. But, we did not detect any association between the other clinical characteristics, such as diseases severity, attack frequency etc. (Table 1) and the specific mutations or genotypes.

As E148Q is one of the common mutations in Turkish patients with FMF, the screening of E148Q mutation in a healthy Turkish cohort also allowed us to determine the E148Q mutation carrier rate in the Turkish healthy population. The carrier frequency of the E148Q mutation has been reported to be $12 \%$ in Turkish population, the present study we found $12 \%$, the frequency in Ashkenazi Jews is $10 \%$, the frequency in Jews of Moroccan origin is $6.4 \%$, and as high as $53 \%$ in Jews from the various ethnic groups $[6,9$, 10]. Several authors have considered E148Q as a mild mutation [38, 39]. Askentijevich et al. has been proposed that E148Q is a polymorphism, not a disease causing mutation, and has a low penetrance [39]. In accordance with this hypothesis, healthy individuals have been found to be homozygous for the E148Q variation [6, 9, 39]. Yilmaz et al. showed that the distribution of the E148Q MEFV mutation among healthy individuals (E148Q 12\%) was significantly different $(\mathrm{P}<0.005)$ from that found in patients (E148Q $3.55 \%$ ) [10]. They found $3.5 \%$ for E148Q carrier rate in patients group unlike our study. Tchernitchko et al. stated that the frequency of the E148Q allele was be similar in patients and healthy controls $(3.62 \%$ and $3.75 \%$, respectively, $p=0.93$ ) [40]. Present study was showed that carrier frequencies were far higher among patients with FMF $(19.1 \%)$ than among healthy carriers (12\%). 11 of 36 E148Q compound heterozygotes $(30.5 \%)$ were asymptomatic; the remaining patients had typical FMF attacks. Thus our results do not completely rule out the possibility that the E148Q mutation has an upregulating effect on inflammation in both FMF and other chronic inflammatory processes. We believe that symptomatic individuals who are E148Q carriers in patients group may be cosegregation with diseases causing unknown mutations in the east of Anatolia region. Thus, we planned a new study to detect of diseases causing unknown mutations by MEFV gene sequencing analysis in patients with E148Q compound heterozygotes and heterozygotes in our region.

It became evident that FMF is not fully recessive and some heterozygous patients tend to have relatively mild disease, but the disease cannot be distinguished clinically from that in homozygous patients [41]. Initially, some investigators assumed that these patients harbor less common $M E F V$ mutations on the second allele in $M E F V$, but a number of investigators have failed to detect when complete sequencing of the gene was performed [38, 42, 43]. Our results are highly consistent with the existence of a clinical phenotype among some patients heterozygous for FMF and, thus, have several important implications. First, in some cases, FMF can be viewed as a dominant condition with low penetrance. A few reports of families with seemingly dominant inheritance have been published [44, 45]. Second, these patients have other periodic fevers, such as TRAPS, HIDS, or cryopyrin-associated periodic syndromes (CAPS), cannot be completely excluded. A few recent reports have described patients who are compound heterozygotes for mutations in 2 known recurrent fever genes [46-48]. These patients were found to have 2 or more reduced penetrance mutations, such as E148Q in MEFV, R92Q or P46L in TNFRSF1A, V377I in MVK, and V198M in CIAS1. In some cases, patients presented with symptoms of both diseases or with a more severe disease, and their treatment was also compromised due to unknown gene interactions among mutations in the known recurrent fever genes [49]. Third, previous studies in FMF patients showed that the presence of modifying alleles in MICA and SAA are associated with a severe FMF phenotype and susceptibility to amyloidosis $[4,50]$. Fourth, the proportion of patients with a single mutation varies between $16.5 \%$ and $33.8 \%$ [ 51 , $52]$. The frequency of patients with one mutations in present study were $40.2 \%$. Single-mutation FMF may be much more common than has previously been thought. The detection of a single mutation appears to be sufficient in the presence of clinical symptoms for the diagnosis of FMF and the initiation of a trial of colchicine.

Papodopoulos et al. reported that the integrated knowledge of molecular genetics characterizing FMF in Turkey will facilitate the diagnosis and clinical decision especially in patients with atypical symptoms. For example, there are regions, such as the Aegean region, represented by Izmir, and territories where the majority of patients with FMF do not exhibit any MEFV mutations. This is totally the reverse in other cases, as Southeastern Turkey, where the presence of a MEFV mutation is obligatory to diagnose FMF. Turkish FMF patients are characterized by an increased genetic heterogeneity, explained by the intrapopulation differentiation [53]. Our patient group was more heterogeneous, because of the ethnic and cultural interactions in the east of Anatolia region of Turkey, than the patients group included the previous studies that were carried out in different regions of Turkey. It should be noted that the 
FMF patients in our study had a broad spectrum of mutations, which may reflect the intercultural interactions of the ancient ethnic groups who lived in the east of Anatolia. Thus, the regional origin should be regarded as a determining factor in tailoring the diagnosis of FMF in Turkish patients. Previously reported studies showed the importance of the region of residence on disease severity [23]. The different results of studies which carried out in different regions but in similar ethnic groups show us that regional studies are as important as ethnic origin-based studies [53].

Kelly et al. emphasize that genetic counseling is an educational process that seeks to assist affected and at-risk individuals to understand the nature of the genetic disorder, its transmission and the options open to them in the management of the disease and family planning [54]. Such knowledge can improve their understanding and eliminate wrong beliefs and conceptions about this disorder. Frequently, people have attributed their disease to the wrong cause, leading to unjustified guilt feelings [55]. It seems that close collaboration between the treating physician and the genetic counselor would be of great benefit and value to FMF patients and their families. The intermarriage rate differs regionally in Turkey. For example, the incidence of intermarriage in the east of Anatolia region and The Aegean region in Turkey were as $33 \%$ and $1.4 \%$, respectively [ 56 , 57]. Intermarriage between relatives may be increased the rate of diseases with autosomal recessive inheritance as FMF. Thus, we suggest that genetic counseling of FMF patients in Turkey should be different from other nations such as Turks, North African and Ashkenazi Jews, and Arabs because of the high incidence of intermarriage rate in the east of Anatolia. Firstly, we advise to get genetic testing done for the children and the spouses of such patients. Secondly, we recommend that all the intermarried couples with MEFV gene mutation carrier should be strongly monitor their future pregnancies by prenatal diagnosis to exclude the possibility of a homozygotes mutation carrier.

Our data imply that despite the heterogeneity, molecular diagnosis appear to be feasible in most patients, because a molecular diagnosis technique did not found MEFV gene mutation in only seven out of 415 patients. As we observed clinical heterogeneity and a high frequency of symptoms, our view is that symptomatic patients with heterozygote or negative patients with recurrent fevers and an increase in acute phase reactants during the attacks require colchicine treatment until as yet undetermined modifier genes or environmental factors are found, especially in the areas where the disease is prevalent. Those cases have to be detected as early as possible to arrange for treatment and adequate genetic counseling.

In conclusion, this study allowed us establishing the spectrum of the MEFV mutations among FMF patients in the east of Anatolia region of Turkey. The most important features were the predominance of the M694V mutation and the low frequency of non-mutated alleles. The molecular analysis of the MEFV gene is the only objective test that confirms the diagnosis in our cohort. A genotype-phenotype correlation showed a relationship between the M694V mutation and the earlier of onset of the disease. Many ethnic groups live in Anatolia and more ethnic origin-based studies are needed to determine the real effect of these mutations. Our study also confirms the mutational heterogeneity of FMF in Turkey. In addition, different intermarriage rates may be one reason for different mutation profiles in Turkey.

\section{REFERENCES}

[1] The French FMF Consortium. A candidate gene for familial mediterranean fever. Nat Genet 1997; 17: 25-31.

[2] Livneh A, Langevitz P, Zemer D, et al. Criteria for the diagnosis of familial mediterranean fever. Arthritis Rheum 1997; 40: 1879-85

[3] Kastner DL, Aksentijevich I. Intermittent and periodic arthritis syndromes. In: Koopman WJ, Moreland LW, Eds. Arthritis And Allied Conditions: A Textbook Of Rheumatology. $15^{\text {th }}$ ed. Philadelphia: Lippincott Williams \& Wilkins 2005; pp. 1411-61.

[4] Touitou I, Picot MC, Domingo C, et al. The MICA region determines the first modifier locus in familial mediterranean fever. Arth Rheum 2001; 44; 163-9.

[5] Ozen S, Hoffman HM, Frenkel J, Kastner D. Familial Mediterranean Fever (FMF) and beyond: A new horizon. Fourth international congress on the systemic autoinflammatory diseases held in Bethesda. Ann Rheum Dis 2006; 65: 961-4.

[6] Ben-Chetrit E, Levy M. Colchicine update. Semin Arthritis Rheum 1998; 28: 48-59.

[7] Pras E, Livneh A, Balow JE, et al. Clinical differences between North African and Iraqi Jews with Familial Mediterranean Fever. Am J Med Genet 1998; 13: 75: 216-9.

[8] Kogan A, Shinar Y, Lidar M, et al. Common MEFV mutations among Jewish Ethnic groups in Israel: High frequency of carrier and phenotype 111 states and absence of a perceptible biological advantage for the carrier state. Am J Med Genet 2001; 102: 272-6.

[9] Stoffman N, Magal N, Shohat T, et al. Higher than expected carrier rates for Familial Mediterranean Fever in various jewish ethnic groups. Eur J Hum Genet 2000; 8: 307-10.

[10] Yilmaz E, Ozen S, Balci B, et al. Mutation frequency of Familial Mediterranean Fever and evidence for a high carrier rate in the Turkish population. Eur J Hum Genet 2001; 9: 553-5.

[11] Yalcinkaya F, Cakar N, Misirlioğlu M, et al. Genotype-phenotype correlation in a large group of turkish patients with familial mediterranean fever: evidence for mutation-independent amyloidosis. Rheumatology (Oxford) 2000; 39: 67-72.

[12] Hiller S, Kohl A, Fiorito F, et al. NMR structure of the apoptosisand inflammation-related NALP1 pyrin domain. Structure (Camb) 2003; 11: 1199-205.

[13] Mcdermott MF. A common pathway in periodic fever syndromes. Trends Immunol 2004; 25: 457-60.

[14] Chae JJ, Komarow HD, Cheng J, et al. Targeted disruption of pyrin, the fmf protein, causes heightened sensitivity to endotoxin and a defect in macrophage apoptosis. Mol Cell 2003; 11: 591-604.

[15] Stehlik C, Lee SH, Dorfleutner A, Stassinopoulos A, Sagara J, Reed JC. Apoptosis-associated speck-like protein containing a caspase recruitment domain is a regulator of procaspase-1 activation. J Immunol 2003; 171: 6154-63.

[16] Sohar E, Gafni J, Pras M, et al. Familial Mediterranean Fever. A survey of 470 cases and review of literature. Am J Med 1967; 43: 227-53.

[17] Samuels J, Aksentijevich I, Torosyan Y, et al. Familial Mediterranean Fever at the millennium. Clinical spectrum, ancient mutations, and a survey of 100 American referrals to the National Institutes of Health. Medicine (Baltimore) 1998; 77: 268-97.

[18] Rogers DB, Shohat M, Petersen GM, et al. Familial Mediterranean Fever in Armenians: autosomal recessive inheritance with high gene frequency. Am J Med Genet 1989; 34: 168-72.

[19] Medlej-Hashim M, Delague V, Chouery E, et al. Megarbane, amyloidosis in Familial Mediterranean Fever patients: correlation with MEFV genotype and SAA1 and MICA polymorphisms effects. BMC Med Genet 2005; 10; 5-4.

[20] Langevitz P, Livneh A, Neumann L, et al. Prevalence of ischemic heart disease in patients with familial Mediterranean fever. Isr Med Assoc J 2001; 3: 9-12.

[21] Oberkanins C, Weinhausel A, Krieqshauser G, et al. Genetic testing for Familial Mediterranean Fever in Austria by means of reverse-hybridization teststrips. Clin Chem 2003; 49: 1948-50.

[22] Eisenberg S, Aksentijevich I, Deng Z, Kastner D, Matzner Y. Diagnosis of Familial Mediterranean Fever by a molecular genetic method. Ann Intern Med 1998: 129: 539-42. 
[23] Akin H, Onay H, Turker E, Cogulu O, Ozkinay F. MEFV mutations in patients with Familial Mediterranean Fever from the aegean region of Turkey. Mol Biol Rep 2009; [Epub ahead of print].

[24] Ozturk A, Ozcakar B, Ekim M, Akar N. Is MEFV gene Arg202GLN (605 G[A) A disease-causing mutation? Turk J Med Sci 2008; 38: 205-8.

[25] Solak M, Yildiz H, Koken R, et al. Analysis of Familial Mediterranean Fever gene mutations in 202 patients with familial mediterranean fever. Genet Test 2008; 12:341-4.

[26] Sahin FI, Yilmaz Z, Yurtcu E, Baskin E. Comparison of the results of PCR-RFLP and reverse hybridization methods used in molecular diagnosis of FMF. Genet Test 2008; 12: 171-4.

[27] Pasa S, Altintas A, Devecioglu B, et al. Familial Mediterranean Fever gene mutations in the southeastern region of Turkey and their phenotypical features. Amyloid 2008; 15: 49-53.

[28] Yigit S, Bagci H, Ozkaya O, Ozdamar K, Cengiz K, Akpolat T. MEFV mutations in patients with Familial Mediterranean Fever in The Black Sea Region of Turkey: Samsun experience [Corrected]. J Rheumatol 2008; 35: 106-13.

[29] Taştan H, Ayvalı C, Durgun IS. Direct detection of common mutations in the Familial Mediterranean Fever gene by using PCR methods. J Med Sci 2004; 24: 445-9.

[30] Evliyaoglu O, Bilici S, Yolbas I, Kelekçi S, Sen V. Diyarbakır Yöresi Ailevi Akdeniz Atesli Çocuklarda MEFV Gen Mutasyon Sıklıkları. Dicle Tıp Dergisi 2009; 36: 80-4.

[31] The Turkish FMF Study Group. Familial Mediterranean Fever (FMF) in Turkey: The results of a nationwide multicenter study. Medicine (Baltimore) 2005; 84: 1-11.

[32] Al-Alami JR, Tayeh MK, Najib DA, et al. Familial Mediterranean Fever mutation frequencies and carrier rates among a mixed arabic population. Saudi Med J 2003; 24 : 1055-9.

[33] Duşunsel R, Dursun I, Gunduz Z, Poyrazoğlu MH, Gurgoze MK, Dundar M. Genotype-phenotype correlation in children with Familial Mediterranean Fever in a Turkish population. Pediatr Int 2008; 50: 208-12.

[34] Brik R, Shinawi M, Kepten I, Bernat M, Gershoni-Baruch R. Familial Mediterranean Fever: clinical and genetic characterization in a mixed pediatric population of Jewish and Arab patients. Pediatrics 1999; 103: E70.

[35] Chen X, Fischel-Ghodsian N, Cercek A, et al. Assessment of pyrin gene mutations in turks with Familial Mediterranean Fever (FMF). Hum Mutat 1998; 11: 456-60.

[36] Olgun A, Akman S, Kurt I, et al. MEFV mutations in Familial Mediterranean Fever: Association of M694V hemozygosity with arthritis. Rheumatol Int 2004; 15: 1-9.

[37] Tunca M, Akar S, Onen F, et al. Turkish FMF Study Group. Familial Mediterranean Fever (FMF) in Turkey: Results of a nationwide multicenter study. Medicine (Baltimore) 2005; 84: 111 .

[38] Bernot A, da Silva C, Petit JL, et al. Non-founder mutations in the mefv gene establish this gene as the cause of Familial Mediterranean Fever (FMF). Hum Mol Genet 1998; 7: 1317-25.

[39] Askentijevich I, Torosyan Y, Samuels J, et al. Mutational and haplotype studies in Familial Mediterranean Fever reveal new ancestral relationships and evidence for a high carrier frequency with reduced penetrance in the Ashkenazi Jewish population. Am J Hum Genet 1999; 64: 949-62.

[40] Tchernitchko D, Legendre M, Cazeneuve C, Delahaye A, Niel F, Amselem S. The E148Q MEFV allele is not implicated in the development of familial Mediterranean fever. Hum Mutat 2003; 22: $339-40$.
[41] Lachmann HJ, Sengul B, Yavuzsen TU, et al. Clinical and subclinical inflammation in patients with Familial Mediterranean Fever and in heterozygous carriers of MEFV mutations. Rheumatology (Oxford) 2006; 45: 746-50.

[42] Tchernitchko D, Moutereau S, Legendre M, et al. MEFV analysis is of particularly weak diagnostic value for recurrent fevers in western European Caucasian patients. Arthritis Rheum 2005; 52. 3603-5.

[43] Booty MG, Chae JJ, Masters SL, et al. Familial Mediterranean Fever with a single MEFV mutation: Where is the second hit? Arthritis Rheum 2009; 60(6): 1851-61.

[44] Booth DR, Gillmore JD, Lachmann HJ, et al. The genetic basis of autosomal dominant familial Mediterranean fever. QJM 2000; 93: 217-21.

[45] Aldea A, Campistol JM, Arostegui JI, et al. A severe autosomaldominant periodic inflammatory disorder with renal AA amyloidosis and colchicine resistance associated to the MEFV H478Y variant in a Spanish kindred: an unusual Familial Mediterranean Fever phenotype or another MEFV-associated periodic inflammatory disorder? Am J Med Genet A 2004; 124A: 67-73.

[46] Singh-Grewal D, Chaitow J, Aksentijevich I, Christodoulou J. Coexistent MEFV and CIAS1 mutations manifesting as Familial Mediterranean Fever plus deafness [letter]. Ann Rheum Dis 2007; 66: 1541 .

[47] Stojanov S, Kastner DL. Familial autoinflammatory diseases: Genetics, pathogenesis and treatment. Curr Opin Rheumatol 2005; 17: 586-99.

[48] Touitou I, Perez C, Dumont B, Federici L, Jorgensen C. Refractory auto-inflammatory syndrome associated with digenic transmission of low-penetrance tumour necrosis factor receptor-associated periodic syndrome and cryopyrin-associated periodic syndrome mutations. Ann Rheum Dis 2006; 65: 1530-1.

[49] Arkwright PD, McDermott MF, Houten SM, et al. Hyper IgD syndrome (HIDS) associatedwith in vitro evidence of defective monocyte TNFRSF1A shedding and partial response to TNF receptor blockade with etanercept. Clin Exp Immunol 2002; 130: 484-8.

[50] Cazeneuve C, Ajrapetyan H, Papin S, et al. Identification of MEFV-independent modifying genetic factors for familial Mediterranean fever. Am J Hum Genet 2000; 67: 1136-43.

[51] Federici L, Rittore-Domingo C, Kone-Paut I, et al. A decision tree for genetic diagnosis of hereditary periodic fever in unselected patients. Ann Rheum Dis 2006; 65: 1427-32.

[52] Padeh S, Shinar Y, Pras E, et al. Clinical and diagnostic value of genetic testing in 216 Israeli children with Familial Mediterranean fever. J Rheumatol 2003; 30: 185-90.

[53] Papadopoulos V, Mitroulis I, Giaglis S. MEFV heterogeneity in Turkish Familial Mediterranean Fever patients. Mol Biol Rep 2009; [Epub Ahead Of Print].

[54] Kelly TE. Clinical genetics and genetic counseling. Chicago: Year Book Medical 1986.

[55] Kessler S, Kessler H, Ward P. Psychological aspects of genetic counseling. III. Management of guilt and shame. Am J Med Genet 1984; 17: 673-9.

[56] Tuncbilek E. Clinical outcomes of consanguineous marriages in Turkey. Turk J Pediatr 2001; 43: 277-9.

[57] Turkiye Nufus ve Saglık Araştırması TNSA 2003, Analiz ve Rapor, Hacettepe Universitesi Nufus Etutleri Enstitusu, Ankara, 2004. Available at: www.hips.hacettepe.edu.tr/tnsa 2003/analizra por.htm-15k. 